\title{
Poverty and Health Issues in the Northern Part of Ghana
}

\author{
Yuanwang Xu (Associate Professor) \\ Jiangsu University, School of Management, Zhenjiang, China \\ Atuahene Antwiwaa Nana Abena \\ Overseas Education College \\ School of Management, Jiangsu University, Zhenjiang, China \\ Ernest Kay Bakpa \\ Overseas Education College \\ School of Finance and Economics, Jiangsu University, Zhenjiang, China
}

\begin{abstract}
This paper examines the impact of poverty on health-related issues in the northern part of Ghana for the period between 1980 and 2017. A secondary data from Ghana Statistical Service Department and the World Bank database was use for the study and a Stata was used in estimating the impact.Results from the study show that, poverty has a great influence on health in the Northern part of Ghana. The study also revealed that, health facilities available in the regions are not fully equipped to solve infant and maternal issues in the regions. Trained public health workers and health services providers are inadequate in the regions hence health education is lacking among pregnant and lactating mothers in the areas of nutrition and malaria prevention. The study, therefore, recommends that government should improve the standard of living among people in the northern regions by providing job opportunities for citizens. There should also be an enhancing health services in the regions, assisting peasants' farmers with modern methods of crop production, and providing equal opportunities for men and women in the regions.
\end{abstract}

Keywords: poverty; health; child mortality; climate

DOI: $10.7176 /$ RHSS/9-8-03

Publication date: April $30^{\text {th }} 2019$

\section{INTRODUCTION}

Poverty has all the time been a portion of the globe, yet the advanced countries where it is imagined that every person is wealthy or well off, some persons are homeless, they find themselves surviving on the streets due to poverty. The undeveloped nations who have discover themselves in various financial conditions; it's not very exciting on the issue of poverty, as large number of individuals live less than one dollar a day. The agenda of ending poverty global by the year 2015 through the Millennium Development Goal (MDG), but poverty still has a strong effect on various countries in the world. From the look of things, the agenda of the MDG has a long way to go, as the economy of the world, day in day out, falls into crisis due to one reason or the other.

Poverty is not a simple notion to define. As a result, a scope of descriptions remains, influenced by diverse disciplinary perspective and doctrines. The dominant Western definition since World War II has defined poverty in monetary terms, using levels of income or consumption to measure poverty(Grusky, Kanbur, \& Sen, 2006) and defining the underprivileged by a census of those who are below a given income/consumption level or 'poverty line'(Lipton \& Ravallion, 1995).

However, this economic description has been complemented in current years by other concepts that explain poverty in a more four-dimensional form. These concepts include the fundamental needs concept, the capabilities concept (Sen, 1999) and the human development concept (McGillivray, 1991). Their agreement is reflected in the extensive use of the United Nations Development Program's (UNDP) Human Development Index (HDI), which is a composite portion of three dimensions of human development: (I) life expectancy, (II) educational attainment and (III) standard of living, measured by income in terms of its purchasing power parity.

It is also indicated in the Organization for Economic Co-operation and Development's (OECD) conceptualization of multidimensional poverty, defined as blended forms of deprivation in the economic, human, political, socio-cultural and protective spheres (OECD., 2006). For our aim, poverty is also defined by a sense of powerlessness, dependence and lack of favorable circumstances, self-determination and self-esteem on the part of the underprivileged.

Furthermore, the acceptance of the multi-dimensional of poverty is demonstrated in the range of both quantitative and qualitative mechanical ways accepted to deliberate and measure poverty. In Ghana, the tendency of poverty issues emanating from the country that have faced the regions are the persistent reliance on the trade abroad of a few basic products with little or no value added (cocoa, gold, timber and others). This has made the economy susceptible to price fluctuations dictated by buyers in the advanced economies. 
Our paper seeks to unearth the influence of poverty on health and related matters on the people at the Northern part of Ghana seeking to establish the causes of poverty in the Northern part of Ghana, the effects that poverty has on the people in the Northern part of Ghana and the right way to poverty reduction in the Northern part of Ghana. The study also in other things developed the following hypothesis (i) there is negative relationship between poverty and health (ii) there is a significant connection between poverty and climate change (iii) there is a significant connection between poverty and child mortality

\section{Literature review}

With regards to poverty and food security, Ghana was able to meet its Millennium Development Goal (MDG) of halving the proportion of those deprived of food in 2002 and was programmed to attain its MDG poverty objective in 2015. Based on this incredible attainment, the World Bank re-classified Ghana as a lower middle-income country (World Bank, 2012). However, these achievements are unequal across the nation. An important portion of the farming and pastoral inhabitants still encounters severe forms of poverty and food insecurity (Zereyesus, Ross, Amanor-Boadu, \& Dalton, 2014).

Many of the population in the Northern part of Ghana do farm as a primary occupation. They do farming to obtain income to feed on and provide for their basic needs for survival. Many of them do not work on the fields owned by their household. Some work on farmlands own by their family and other are hired by farm owners through some type of communal labor arrangement. The benefits of development in agriculture helps in decreasing poverty, this will help reduce food insecurity and malnutrition among the people in the Northern regions in Ghana. Growth in agriculture will produce more food to feed people in such communities hence create jobs and wealth for the unemployed. This is problematic for the reason that, farming or farm management is the main source of daily bread for about 50\% of households in the nation(Quaye, Hall, Luzadis, \& sustainability, 2010). The level of Ghana's economic crises is a great factor with poverty. The persistent inflation in prices of products and items makes persons with incomes that do not change unable to face the economy. The agriculture sector is the mainstay of the Ghanaian economy, contributing significantly to Gross Domestic Product and providing a source of livelihood to many low-income families (Quaye et al., 2010). Yet, the agricultural sector is dominated by poor small-scale farmers and remains one of the most climate sensitive sectors in the Northern regions.

One of the major world's valuable resources, which are energy/ crude oil, whenever there is inflation; it affects the level of material comfort of people, as it influences the prices of products and services. For those who live in poverty in the northern part of Ghana, they turn to roll in severe poverty, and people with a normal standard of living, are faced with difficulty when managing their expenses. Spending on social programs for poverty reduction such as health and education has been low and constraining to poverty reduction. For instance, the degree of paying out on health and education at $2.0 \%$ and $2.8 \%$ of GDP subsequently below Ghana averages with an excessive quantity of the resources used for workers' payments and management. For sixty-two years, Ghana has experienced growing and deepening poverty an evidence of intensification of vulnerability and exclusion among some groups and in some areas, especially in the North of the country and the Central region.

The Northern part of Ghana has been identified as a particularly vulnerable region to the changing climate (Antwi-Agyei, Fraser, Dougill, Stringer, \& Simelton, 2012).

Northern Ghana is a region where relatively minor rainfall variability or perturbations can lead to significant impacts on crops yield, because of limited adaptive capacity(Antwi-Agyei et al., 2012). The Northern region has been characterized by extreme events such as floods and droughts and these have often resulted in extensive damage to crops and livestock leading to famine (Brown \& Crawford, 2008). An increase in temperature and extreme weather events has been anticipated through all environmental areas of Ghana (Brown \& Crawford, 2008). These extreme events have been projected to increase due to climate change, particularly increasing temperature and erratic rainfall, and these are likely to further worsen occupations in this region (IEA \& Initiative, 2010). Sub-Saharan Africa is extremely susceptible to the adverse impacts of climate change and variability (Field et al., 2014). Climate changeability is a key cause of danger to peasant farmers and pastoralists, mainly in arid land areas. A developing form of indication connects climate-related hazard to the level and the continuing of rural poverty in these locations. Occurrence is frequently high in the arid lands, where climate changeability uncovers peasant farmers and pastoralists to key threat(Hansen et al., 2019). Climate variation has physical influences on human well-being, the psychological well-being influences seem unclear. Climatic variations appear to impact human healthiness in several means (Acharibasam \& Anuga, 2018).For example, anthropogenic climate variation influences have been connected to mental disorders in persons comprising nervousness, temperament disorders, strain, downheartedness, post-traumatic strain disorders, fierceness and feeling of desperateness(Acharibasam \& Anuga).Also, fright, hopelessness, suicidal reflection, increased drug misuse, and heat connected bereavements have been related to hostile climatic variations (Acharibasam \& Anuga, 2018).Climate variation influences individuals through dissimilar ecological variations comprising acute weather events, sub-acute weather events, and long-term weather events (Acharibasam \& Anuga, 2018). Acute impacts often comprise events such as downpours, forestry fires and hurricanes that rendering people to immediate mental damages (Doherty \& Clayton, 
2011). Sub-acute effects comprise strong feelings related with people vicariously seeing climate change effects; anxiety linked to distrust regarding the point of current and future threats that persons and other species may encounter (Maibach, Roser-Renouf, \& Leiserowitz, 2008). Long-term ecological effects involve large-scale social and society effects establishing in the forms of heat-related fierceness, fights over rare resources(Nordås \& Gleditsch, 2007), dislocation and involuntary movement (Acharibasam \& Anuga) and chronic ecological strain (Albrecht, Mundlos, \& development, 2005). These events often result in loss of employments, reduced socioeconomic activities, and loss of sense of place which may aggravate psychological health hazards. In Northern Ghana, peasant farmers seem to be at a higher danger of anguish acute, subacute, and long-term effects of climate variation happenings due to the unusual ecological encounters they face (Dumenu, Obeng, \& Policy, 2016). Northern Ghana's savanna landscape is mainly a dry zone with extreme droughts, and the rising weather variation levels constantly exposes peasant farmers to hostile climatic conditions comprising poor rainfall patterns, forest fires, soil erosion, and loss of soil fertility, poor harvest, and damage of property and livestock (Acharibasam \& Anuga, 2018). Thus, the chronically rising pace of altering climatic conditions is a developing danger to the psychological health of farmers(Laube, Schraven, \& Awo, 2012)

Farmers in Northern Ghana are exposed to atmospheric conditions due to farm characteristics, such as low income from rain fed agriculture, inadequate information, absence of expertise ,lack of access to sufficient and upgraded agricultural machinery and stocks, storage facilities for water and produce, and other framework(Acheampong, Ozor, \& Owusu, 2014).The insignificant in poverty and food insecurity in the north may be mainly reflective of the region's made higher percentage of farming for basic needs, which is dependent on climate sensitive factors, and much lower rate of urbanization. The underprivileged and most susceptible groups in the Northern part of Ghana are likely to be most influenced, women are especially susceptible to environmental destruction. Certainly, women grieve unequal economic and other injuries in result of environmental degradation has been well documented (Glazebrook, 2011) Northern part of Ghana, there is no infrastructure or technology to give irrigation, so women in farming greatly rely on the weather, they depend on the rainy period and have only one growing phase each year. Crop losses are important because they influence nutrition, and malnourishment in children can have lifelong results.

Despite the truth that the country has made extraordinary advancement in her poverty reduction push over the past sixty-two years, the North still files the topmost levels of poverty. The Ghana living standard study implies that poverty is more severe in food crop growing areas in comparison to the cash crop growing ones(Hatskevich, Jenicek, \& Darkwah, 2011). Ghanaians in the Northern regions are confronted with dangers and vulnerabilities but poor people, especially those living in pastoral areas dependent on agriculture and in warm and humid ecologies face more than others. This is fact of a big percentage of SSA's population. There are a number of dangers and exposure that drive and keep up poverty in SSA, involving harvest breakdown, market collapse and volatility, battle, and wellbeing shocks. The top level of poverty in association with women in the Northern Regions go to the extent of generating maternal mortality as going for antenatal care always tends to be a problem. Every now and then mothers pass away during child bearing all in the name of poverty. According to MDG's report motherly death is among the health signs that demonstrate the tremendous gap between the rich and the poor.

\section{Poverty and Health}

The worldwide MDG 5 goal for maternal health is to lower the total of mothers who die in pregnancy and childbearing by three quarters between 1990 and 2015. When applying this aim to Ghana, motherly deaths should fall to 145 cases per 100,000 live births. In the period 2007-12 Ghana had an investigated motherly deaths ratio of 450 deaths per 100,000 live births (this figure was estimated at 350 deaths per 100,000 by (UN agencies/World Bank in 2010). As Ghana's motherly deaths rate is three times higher than the given aim, it is impossible to attain MDG 5 by 2015. Part of the goal also imposes that 100 per cent of births must be handled by a skilled health professional. In the time 2007-11 this figure positioned at 68 per cent, so advance towards this goal is also now off track. Poverty alleviation fund managers- SEND-Ghana is dismay by the soaring rise in motherly deaths in the Northern Region.

The country approved to the Millennium Development Goals (MDG) obtained from the 2000 UN Millennium Declaration and has made great actions towards achieving several of them. Most remarkable are probably the attainments made for Goals One and Two, which address severe poverty and hunger, as well as education, precisely. However, Ghana has failed on reaching several other objectives related to health. Infant and child mortality, one of the problems discussed in the MDG, remains high, as does motherly deaths, indeed; circumstances for pregnant mothers have been worsening for sixty-two years. Other acute issues not discussed in the MDG cause even more dangerous harm for the health of the Ghanaian populace. Malaria, transferred by the Anopheles mosquito, is one of the most severe illnesses in the country, both by infection and mortality rate.

Women in the Northern part of Ghana also commonly experience higher menace of ill well-being and poor nutrition owing to both biological and social susceptibilities, such as increased nutrient requirements during pregnancy and lactation, combined with physically demanding agricultural work and domestic responsibilities, 
and poor nutrient intakes (Harris, 2014). Furthermore, women who work long periods in agriculture may be less expected to pursue health services outside the household, which can decrease the possibility of child immunization, health check-ups, and access to other health and diet information (Bhalotra, 2010). Malnutrition at the early phases of life does not only influence the health results of the child, but it also has a severe unfavorable influence on the elements of their incomes, such as physical and intellectual development, school performance and eventual future incomes and productivity. Most children in the Northern part of Ghana are malnourished due to poverty in the region. Women and families do not have enough resources to cater and feed their children as persons get locked up in a vicious phase of deprived health, lower learning ability, reduced physical activity, and lower productivity as a result of poverty, malnutrition and poor child health link, the gains from former economic development may be endangered (Bagriansky, 2010). Lack of dietary diversity is a problem at any age among children, but it is mostly serious for preschoolers and young children throughout the complementary feeding stage, who need diet including vital nutrients for normal physical and mental development. Low nutritional diversity is significantly related with wasting among pastoral children. Poor nutrition, inadequate hygiene, living conditions, income and medical care can lead to preventable infection and disease among children in the Northern part of Ghana.

The high incidence of Low Birth Weight could also be due to inadequate gain to health facilities such as prenatal services due to socio economic obstacles which are established to be strongly linked to gain to sufficient antenatal services. About half of the populace in the region live in rural areas and for that matter the residents have limited access to health facilities due to the deprived nature of their populations.

They also lack access to societal conveniences such as electricity; good roads, drinkable water and as an effect trained midwives do not want to admit positions in to these societies. However, it must be said that the Government of Ghana has now put dealings in place to advance access to antenatal services by making antenatal care services unrestricted for all expecting women across the country, the accomplishment of these plan is limited due to socioeconomic obstacles.

Other evidence adduced by (Abubakari, Kynast-Wolf, Jahn, \& childbirth, 2015) shows that low socioeconomic prestige and use of facilities such as prenatal care services and tetanus immunization could affect birth weight. Therefore, if the Government program were prepared towards developing education of the girl child, which is very low in the North as well as contact to reproductive health and reduction of poverty in the area, it would perform a critical function towards improving the baby birth weight in Northern Ghana. The low incidence of low birth weight in the reserved hospital was anticipated because the mothers who give birth in the private health centers are from high earning class of the community and have a high socioeconomic class as equated to those who give birth in the public health center. High socio-economic position is found to have a positive influence on delivery result. Furthermore, Ghana's Government has increased its expenditure for healthcare more than threefold within a decade, healthcare infrastructure is still patchy and insufficient, mostly external of a metropolitan area such as Accra. Within cities, hospitals and emergency services are available, but not quite up to Western standards.

The availability of healthcare centers and even medical practitioners is very short in the countryside, and traditional herbal medicine is the go-to option for great portions of the rural population that cannot afford migrating long distances for healthcare. Prior to 2003, the healthcare reportage of Ghana's habitants was oftentimes lacking, to say the least. The "cash and carry" scheme enforced the ill to grant for their medical care up front - not possible for large parts of the residents. In an attempt to fight this case, the Ghanaian Government has set up the National Health Insurance Scheme (NHIS). Outcomes were almost instant, with the nation noticing a plunge in deaths and a rise in patient numbers. The duties of the NHIS are tailored towards the essentials of Ghanaians: treatments for malaria, diarrhea, respiratory diseases, diabetes, hypertension and other widespread illnesses are examined. Premiums are set at adaptable rates ranging from 7.20 GHS to 48.00 GHS to make the scheme available even to low-salary workers in the non-formal or self-employed sector. However, there is a period of waiting of six months after requesting for the scheme for persons employed in above sectors. Apart from Government-funded medical institutions, Surgery center, Outpatients Department and Healthcare centers established by religious bodies play a vital role in providing the inhabitants with much-needed medical assistance.

Records from the Northern Regional Health Directorate revealed that 57 motherly deaths have so far been noted for the mid-year of 2015.A detailed list of statistics showed that 212 maternal deaths were recorded in 2012 against that of 2013 which dropped to 99 . The death toll further reduced to 66 in 2014 which the regional health directorate defined as positive change. In the Northern part of Ghana, women who were married, less educated, unemployed, and poor do attend lower parental care maternity center. Additionally, women who delivered in health centers or public facilities, or received care from nurses and other care providers, who do not give them much attention, respect and education due to large number of women in the hospital. In most cases, pregnant women outnumber the number of health care providers in the regions. This results high incidence of child mortality and maternal mortality in the region.

Maternal mortality issues have become a major cause for concern especially in developing counties as they struggle to attain the Sustainable Development Goals. Traditional Birth Attendants (TBAs) have played a significant role in providing maternal health services, especially in rural Africa. In the Northern part of Ghana, 
most women do not have access to a skilled birth attendant which invariably leads to the rising maternal and infant mortality. TBA is "a person who assists the mother during childbirth and initially acquired her skills by delivering babies herself or through apprenticeship to other TBAs". Traditional Birth Attendants (TBAs) stand to help reduce maternal and child mortality in the region. According to (Harvey et al., 2007). Traditional Birth Attendants (TBA) have been in existence as long as the human race has inhabited the earth. TBAs play an important role as far as the delivery of maternal care is concerned, especially in rural areas. According to(Lane \& Garrod, 2016), TBAs are more geographically accessible and culturally acceptable to provide most of the basic but most important care that pregnant women require along with antenatal and post-natal care. Women in the northern part of Ghana has accepted to patronize services provided by TBAs since they can afford it and its accessible to them. TBAs are not professional trained midwives who provide proper care and treatment to mothers after child labor and they do not have their modern facilities to handle babies and mothers after child labor hence increased in child and maternal mortality.

A maternal death is the death of a woman while pregnant or within 42 days of termination of pregnancy, regardless of the period and section of the pregnancy, from any cause linked to or provoked by the pregnancy or its handling but not from unexpected or incidental causes". Maternal mortality is usually from direct or indirect causes. Direct maternal deaths are deaths developing from obstetric difficulties of the pregnant state, from interference, exclusions, improper treatment, or from a chain of occurrences developing from any of the above. Indirect maternal deaths are from earlier disease or from a disease that matured during the pregnancy which was not due to a direct obstetric cause, but was provoked by the physiologic effects of pregnancy. The maternal deaths ratio is the number of maternal deaths through a stated period per 100,000 live births during the same stated period. Maternal death ratio is used as an indicator of the value of health care delivery system of a nation. Maternal mortality is widely avoidable but the greater number of these deaths continues to exist in advancing nations especially those in Sub-Saharan Africa. Ghana is one of the nations battling with a high motherly death and it is making attempts of minimizing it. The misfortune of maternal mortality enlightened spokespersons of some 189 countries at the United Nations millennium summit in September 2000 to commit them to reduce maternal deaths by $75 \%$ by the year 2015 .

The expected rate of decrease of maternal mortality if Millennium Development Goal on maternal health is to be reached should be about 5\% annually from the year 2000. Globally the annual percentage decrease in maternal deaths ratio between 1990 and 2008 was only $2.3 \%$. The maternal death ratio in Sub Saharan African countries was 920 per 100,000 live births in 2000 and 640 per 100,000 live births in 2008. In Ghana there has been a slow decrease of maternal mortality from 503 per 100,000 live births in 2005 to 451 per 100,000 live births in 2008. Many nations in Sub-Saharan Africa where the burden of maternal mortality is very high having made no advancement. The burden of maternal death in Sub-Saharan Africa is a serious challenge.

The teaching and regional hospitals have higher statistics than the national average since most of the very sick patients are usually transfer to these tertiary centers for management. Maternal deaths have formerly not been considered at the Tamale Teaching Hospital but being the main transfer hospital in northern Ghana, its institutional figures from internal audits over the past years have been unacceptably high. The objective of this review was to determine the annually maternal death ratio over the time 2006-2010 and the trends of direct and indirect causes at the Tamale Teaching Hospital.

Malaria provides significantly to the poor health condition in the Northern region of Ghana while infectious diseases are no longer the primary sources of death in the advanced world, they remain the key reason of death in middle and lower income nations, accounting for more than half of all deaths in Africa (Murray, Lopez, Mathers, \& Stein, 2001). In Northern Ghana, while the expenses of malaria care were just $1 \%$ of the income of the wealthy family, it was $34 \%$ of the income of the meagre families; and malaria incidence is high in rain season, which corresponds with a farming period(Akazili, 2000). According to(Akazili, 2000), malaria spreading depends on the accessibility of mosquito breeding habitat, which is linked to ponding after raindrops, while the production of the breeding habitat is a purpose of the ambient temperature. Malaria does not just cause illness and deaths around the world; it decreases productivity and increases the risk of poverty for the communities and countries affected. For example, the infection rate is highest during the rainy season, often resulting in decreased agricultural production.

\section{Data and methodology.}

The data for the study was taken from the Ghana statistical service department and the confirmed from the World Bank data base. We use some econometric model in developing the model for the study. The model was developed because of the study hypothesis and the study question and using Stata to run a simple OLS model to test the main impact of poverty.

$P=p c i+e d u+u e m p$

Where: $\mathrm{P}=$ poverty edu= education uemp=unemployment $\mathrm{Pci}=$ per capita income???

$H r_{1}=\beta_{0}+\beta_{1} p+\beta_{2} c m+\beta_{3} c l i m+\mu_{1}$ 
Where $\mathrm{hr}=$ health $\mathrm{cm}=$ child mortality $\mathrm{clim}=$ climate change

\section{Results and Interpretation}

From the descriptive statistics, the Mean value of health stand to be 1.791144 obtaining a Standard Deviation of.08432809, which means that the tendency of the data in question is very good for the study, this implies to all the variables under consideration.

Table 1.1 Descriptive statistics

\begin{tabular}{|l|llll|}
\hline variable & mean & Std.Dev & min & max \\
\hline Health & 1.791144 & .8432809 & 1.058659 & 5.464136 \\
Poverty & .0355777 & .0098475 & .013751 & .0465205 \\
CM & 5.09013 & 31.9886 & -26.37222 & 235.47 \\
Climate change & 1.961276 & .2749047 & 1.555981 & 2.511093 \\
\hline
\end{tabular}

Our hypothesis that poverty has a bad result on health and the people of the three Northern regions is accepted, based on the probability $\mathrm{F}$ test which is 0.000 , before a probability can be accepted if the $\mathrm{F}$ test should be less than 0.1 and the tabulated F probability should be less than computed F probability and it is indeed so without data.

Table 1.2 regression result

\begin{tabular}{|l|lll|}
\hline Explanatory Variable & Coe. & $\mathbf{t}$ & $\mathbf{p}>\mathbf{t}$ \\
\hline Poverty & -30.9901 & -5.87 & 0.000 \\
Child Mortality & .0113831 & 15.45 & 0.000 \\
Climate Change & .0361561 & 0.26 & 0.794 \\
-cons & 2.539443 & 11.61 & 0.000 \\
\hline
\end{tabular}

From our regression analysis, it shows that, poverty leave a negative 30.990 impact or effect on health. This means, poverty has a bad effect on health and the people in the Northern part of Ghana and it is accepted or it is significant at 0.000 which is less than 0.05 , this means that, an additional increase in poverty will result to negative 30.9901 effects on health of the people in the Northern regions in Ghana. But the connection is also related to other factors related to poverty, such as lack of information on appropriate health-promoting practices, Ill health, in turn, is a main cause of poverty. This is partially due to the expenses of pursuing health care, which involve not only out-of-pocket expend on care (such as consultations, tests and medicine), but also transportation costs and any informal payments to providers. The control variables that is climate change and infant death, coefficient of climate change is .0361561 and $p>t 0.794$ and coefficient of child mortality is .0113831 and $p>t 0.000$, climate change influences health but it is not significant at 0.794 .

$\mathrm{R}$ square, these talks about the variation in the dependent variables can explain about $60 \%$ of the variation in the dependent variables which describes that our model for the research is valid at $60 \%$ level.

\section{CONCLUSION}

Poverty has all the time been a portion of the globe, yet the advanced countries where it is imagined that every person is wealthy or well off, some persons are homeless, they find themselves surviving on the streets due to poverty. The undeveloped nations who have discover themselves in various financial conditions; it's not very exciting on the issue of poverty, as large number of individuals spend less than one dollar a day. Poverty is a huge problem among the people in the Northern part of Ghana, population status of the people in the Northern sector is huge. Development and growth in the regions is low due to financial instability of Ghana's economy and much resources are not allocated in the regions to solve poverty issues in the regions. Farming is the main occupation among men and women in the regions, most employ the simple method of farming to provide food to feed only their families. Unemployment is high in the Northern part of Ghana, most people in the regions are less educated hence poverty issues regions.

Based on our findings, poverty has a great influence on health in the Northern part of Ghana, health facilities available in the regions are not fully equipped to solve infant and maternal issues in the regions. Trained public health workers and health services providers are inadequate in the regions hence health education is lacking among pregnant and lactating mothers in the areas of nutrition and malaria prevention. We discovered that climate variation has influences on citizens' health in the regions. Also, climate change contributes to poverty in the Northern part of Ghana since it influences agriculture production in the regions. Most farmers in the regions depend on natural rain for the production of crops in the region.

An important initiative to be taken is to improve the standard of living among people in the Northern regions by providing job opportunities for citizens, enhancing health services in the regions, assisting peasants farmers with modern methods of crop production ,providing equal opportunities for men and women in the regions, educating pregnant and lactating mothers in the regions and ensuring weather conditions in the regions should be communicated to citizens which are critical in the growth and development in the regions. 


\section{RECOMMENDATION}

It is recommended that,

1. Government should make sure that all men and women, specifically the underprivileged and the susceptible, have equal privileges to financial resources, as well as access to fundamental facilities, proprietorship and control over land and other modes of assets, inheritance, natural resources, appropriate new technology and financial services, including microfinance

2. Government program can develop child nutrition by ensuring food security at the family or at the individual (child and mother) level. Public Health officials should teach parents and caregivers on the significance of dietary diversity to their children. The government could also take advantage of the structures of the national school feeding program to diversify the diet of the school children.

3. Government and Health Ministries should improve maternal education, income and employment of people in the Northern part of Ghana, this will have strong positive relationship with birth weight under nutrition (low birth weight) and over nutrition (macrosomia) exist together among children at birth in Northern region revealing the twofold stress of malnutrition occurrence, which is presently being experienced by people in the Northern part of Ghana.

4. Climate variation acclimatization program should be planned in a way that improves family adjusting ability in the short-lived whilst supporting their improvement advantages in the long standing. It is essential that improvement associates and program producers develop suitable and robust indicators to evaluate the long standing results of several climate variation adaptation measures in order to decrease maladaptation. Also, strong and productive program interventions for improving mental health care for rural farmers. Mainstreaming the mental effects of weather variation, promoting awareness of mental health dangers through both formal and non-formal education among farmers is also imperative to make farmers emotionally stable to adjust to climate variation. Ghana Meteorological Agency through the state and private media, their news on weather conditions should be directed to the agricultural sector, especially small scale farmers, and it's should be communicated in local languages which is easily understood by local farmers in the Northern part of Ghana.

\section{Reference}

Abubakari, A., Kynast-Wolf, G., Jahn, A. J. B. p., \& childbirth. (2015). Prevalence of abnormal birth weight and related factors in Northern region, Ghana. 15(1), 335.

Acharibasam, J. W., \& Anuga, S. W. Climate Risk Management.

Acharibasam, J. W., \& Anuga, S. W. J. C. R. M. (2018). Psychological distance of climate change and mental health risks assessment of smallholder farmers in Northern Ghana: Is habituation a threat to climate change? , $21,16-25$.

Acheampong, E. N., Ozor, N., \& Owusu, E. S. J. C. c. (2014). Vulnerability assessment of Northern Ghana to climate variability. 126(1-2), 31-44.

Akazili, J. (2000). Economic costs of seeking malaria care to households in the Kassena-Nankana district of Northern Ghana. University of Cape Town,

Albrecht, A., Mundlos, S. J. C. o. i. g., \& development. (2005). The other trinucleotide repeat: polyalanine expansion disorders. 15(3), 285-293.

Antwi-Agyei, P., Fraser, E. D., Dougill, A. J., Stringer, L. C., \& Simelton, E. J. A. G. (2012). Mapping the vulnerability of crop production to drought in Ghana using rainfall, yield and socioeconomic data. 32(2), 324334.

Bagriansky, J. J. T., Albania: MDGF/UN. (2010). The economic consequences of malnutrition in Albania.

Bhalotra, S. J. J. o. D. E. (2010). Fatal fluctuations? Cyclicality in infant mortality in India. 93(1), 7-19.

Brown, O., \& Crawford, A. J. A. S. S. (2008). Climate change: A new threat to stability in West Africa? Evidence from Ghana and Burkina Faso. 17(3), 39-57.

Doherty, T. J., \& Clayton, S. J. A. P. (2011). The psychological impacts of global climate change. 66(4), 265.

Dumenu, W. K., Obeng, E. A. J. E. S., \& Policy. (2016). Climate change and rural communities in Ghana: Social vulnerability, impacts, adaptations and policy implications. 55, 208-217.

Field, C. B., Barros, V. R., Mastrandrea, M. D., Mach, K. J., Abdrabo, M.-K., Adger, N., . . Barnett, J. (2014). Summary for policymakers. In Climate change 2014: impacts, adaptation, and vulnerability. Part A: global and sectoral aspects. Contribution of Working Group II to the Fifth Assessment Report of the Intergovernmental Panel on Climate Change (pp. 1-32): Cambridge University Press.

Glazebrook, T. J. H. (2011). Women and climate change: A case-study from Northeast Ghana. 26(4), $762-782$.

Grusky, D. B., Kanbur, S. R., \& Sen, A. K. (2006). Poverty and inequality: Stanford University Press.

Hansen, J., Hellin, J., Rosenstock, T., Fisher, E., Cairns, J., Stirling, C., . . Campbell, B. J. A. S. (2019). Climate risk management and rural poverty reduction. 172, 28-46.

Harris, J. (2014). Gender implications of poor nutrition and health in agricultural households. In Gender in 
Agriculture (pp. 267-283): Springer.

Harvey, S. A., Blandón, Y. C. W., McCaw-Binns, A., Sandino, I., Urbina, L., Rodríguez, C., . . Djibrina, S. J. B. o. t. W. H. O. (2007). Are skilled birth attendants really skilled? A measurement method, some disturbing results and a potential way forward. 85, 783-790.

Hatskevich, A., Jenicek, V., \& Darkwah, S. A. J. A. T. e. S. (2011). Shea industry-a means of poverty reduction in Northern Ghana. 44(4), 223-228.

IEA, O. J. A. o. t. S. o. E. S., \& Initiative, S. f. t. G.-. (2010). OECD, and World Bank. 2010. 26-27.

Lane, K., \& Garrod, J. J. J. o. g. h. (2016). The return of the traditional birth attendant. 6(2).

Laube, W., Schraven, B., \& Awo, M. J. C. c. (2012). Smallholder adaptation to climate change: dynamics and limits in Northern Ghana. 111(3-4), 753-774.

Lipton, M., \& Ravallion, M. (1995). Poverty and policy. Handbook of development economics, 3, 2551-2657.

Maibach, E. W., Roser-Renouf, C., \& Leiserowitz, A. J. A. j. o. p. m. (2008). Communication and marketing as climate change-intervention assets: A public health perspective. 35(5), 488-500.

McGillivray, M. (1991). The human development index: yet another redundant composite development indicator? World Development, 19(10), 1461-1468.

Murray, C. J., Lopez, A. D., Mathers, C. D., \& Stein, C. (2001). The Global Burden of Disease 2000 project: aims, methods and data sources. In: Citeseer.

Nordås, R., \& Gleditsch, N. P. J. P. g. (2007). Climate change and conflict. 26(6), 627-638.

OECD. (2006). OECD Annual Report 2006: OECD Publishing.

Quaye, A. K., Hall, C. A., Luzadis, V. A. J. E., development, \& sustainability. (2010). Agricultural land use efficiency and food crop production in Ghana. 12(6), 967-983.

Sen, A. (1999). Commodities and capabilities. OUP Catalogue.

Zereyesus, Y. A., Ross, K. L., Amanor-Boadu, V., \& Dalton, T. J. J. K. S. U., Manhattan, KS. (2014). Baseline feed the future indicators for northern Ghana 2012. 33 